\title{
Analisis Densitas Bentik Dinoflagellata Gambierdiscus, Ostreopsis dan Prorocentrum di Pantai Nirwana, Padang
}

\author{
Thamrin* \\ *Pascasarjana Ilmu Lingkungan Program Pascasarjana Universitas Riau, Pekanbaru. \\ *Fakultas Perikanan dan Ilmu Kelautan Universitas Riau, Pekanbaru \\ Koresponden E-mail: thamrin@lecturer.unri.ac.id
}

(Diterima 10 Mei 2020|Disetujui 14 Juli 2020|Diterbitkan 30 Juli 2020)

\begin{abstract}
Environmental degradation has occurred in various ecosystems in the world. This also carries out in the sea and even sometimes threaten human life, whether directly or indirectly. Likewise, events in the marine environment associated with poisoning, caused by toxic algae such as dinoflagellates. To see the progress the survey research was conducted on Thallasia sp to see the growth of toxic dinoflagellates Gambierdiscus, Ostreopsis and Prorocentrum in the Nirwana Coast Padang. The data analysis uses two-way statistics with Turkey's Advanced Test. The results showed that Gambierdiscus and Ostreopsis almost the same number and were still low. High striking results occurred on Prorocentrum which differed markedly from both Gambierdiscus and Ostreopsis. This results also significantly different among stations.
\end{abstract}

Keywords: Thallasia sp., gambierdiscus, ostreopsis, prorocentrum, ciguatera.

Berbagai jenis penyakit selalu dihubungkan dengan perubahan lingkungan. Sumber penyakit mungkin bersifat secara langsung dampaknya terhadap manusia dan mungkin juga tidak langsung. Diantara sumber penyakit yang sedang mengalami peningkatan di perairan laut dikenal dengan nama Ciguatera fish poisoning (CFP). CFP merupakan menjadi permasalahan kesehatan global. Ciguatera adalah fenomena ikan laut terkena racun (mengandung toksin), dimana Bangsa Spanyol mempercayai bahwa penyakitnya berasal dari kelompok siput laut (yang diberi nama 'cigua' di Karibia). Sedang penyebabnya adalah berasal dari kelompok dinoflagellata yang mengandung racun (toksin).

Dinoflagellata memiliki beberapa spesies, dan ada yang mengandung racun dan tidak mengandung racun. Di daerah tropis yang termasuk mengandun racun termasukkelompok Gambierdiscus, Prorocentrum dan Ostreopsis. Dinoflagellata dalam hidupnya umumnya sebagai plankton. Tetapi ketiga dinoflagellata ini sebagian besar waktu hidupnya menempel pada substrat dasar dalam perairan, yang menyebabkan pengelompokkannya ke dalam organisme bentik. Prorocentrum dan Ostreopsis menghabiskan sebagian besar hidupnya menempel pada berbagai substrat, termasuk patahan karang batu yang telah mati (rubles), pasir, beragam makro-algae, sea grass, substrat pasir, dan lain-lain substrat yang berada di perairan laut.

Bila manusia terpapar dengan ciguatera memiliki simtommungkin saja secara neurological, gastrointestinal and cardiac. Ikan yang telah mengakumulasi toksin ciguatera yang diproduksi dinoflagellata bisa termakan oleh manusia (Park 1994). Keracunan berat bisa saja terjadi, ataupun paralysis, koma dan sampai kematian manusia. Diperkiraan setiap tahun terdapat 25,000 orang penderita diakibatkan oleh ciguatera diseluruh dunia, dan penyakit tetap meningkat sampai saat ini (Pottier et al.
2001). Perkirakan secara global terdapat satu juta orang terpapar setiap tahun denganciguatera (Harrness, 2005).

Lewis (2001) menghubungkan peningkatan Harmful algal blooms (HAB) di seluruh dunia dengan degradasi kondisi terumbu karang. Kerusakan terumbu karang dunia sudah hampir merata, baik kerusakan secara fisika yang dipengaruhi manusia peningkatan ciguatera yang disebabkan terumbu karang didominasi makroalga yang menyediakan inang bagi dinoflagellata (Kaly \& Jones 1994).

Pengamatan dinoflagellata bentik beracun telah banyak dilakukan di dunia, umpanya di Amerika (Loeblich, 1968; Norris et al., 1985), Mediterranean (Aligizaki and Nikolaidis, 2006; Ismael and Halim, 2006),di Australia (Pearce et al., 2001; Murray et al., 2006), di Jepang (Watanabe et al., 2000; Yamatogi et al., 2005;), di Viatnam (Iwataki et al., 2009), di Singapura (Holmes, 1998), di Malaysia (Chui-Pin et al., 2010, 2011; Al-Has dan Mohammad-Noor, 2011), namun yang dilakukan di Indonesia masih sangat terbatas, dan khususnya di perairan sebelah barat Sumatera mungkin baru beberapa pengamatan dilakukan (Thamrin, tidak dipublikasi).

Dinoflagellata bentik bisa ditemukan pada kolom air, menempel pada pasir, patahan karang mati, seaweed, seagrass, dan ditemukan diseluruh perairan dunia. Dinoflagellata merupakan kelompok produser kedua terbesar setelah diatom dalam food webdi perairan laut. Perairan laut Sumatera Barat memiliki beragam ekosistem termasuk terumbu karang, dan sebagian besar telah mengalami kerusakan. Bila terumbu karang rusak atau mati, dan bagian yang mati tersebut akandidominasimikro-alga dan akan diikuti lamun. Peningkatan dinoflagellata beracun diperkirakan memiliki hubungan dengan degradasi terumbu karang (Kaly \& Jones 1994). Disamping itu juga diperkirakan dominasi lamun merupakan salah satu factor tidak langsung peningkatan bentik 
dinoflagellata beracun akhir-akhir ini, dan untuk melihat pengaruh peningkatan pertumbuhan lamun ini maka dilakukan penelitian ini.

Tujuan penelitian ini adalah 1). Melihat diversitas Ketiga genus Gambierdiscus, Ostreopsis dan Prorocentrum. 2). Menganalisis ketiga genus Gambierdiscus, Ostreopsis dan Prorocentrum.

\section{BAHAN DAN METODE}

\section{Tempat dan Waktu}

Penelitian dilakukuan di Perairan Nirwana Sumatera Barat (Gambar 1) pada tanggal 6 April 2014 (13 Jumadil Akhir $1435 \mathrm{H}$ ) di perairan pantai Nirwana Sumatera Barat. Untuk analisa sampel air untuk Fosfat dan Nitrat dilakukan di Laboratorium Kimia FMIPA Universitas Riau.Sementara untuk penghitungan densitas dinoflagellata dilakukan di Laboratorium Program Studi Ilmu Lingkungan Universitas Riau.

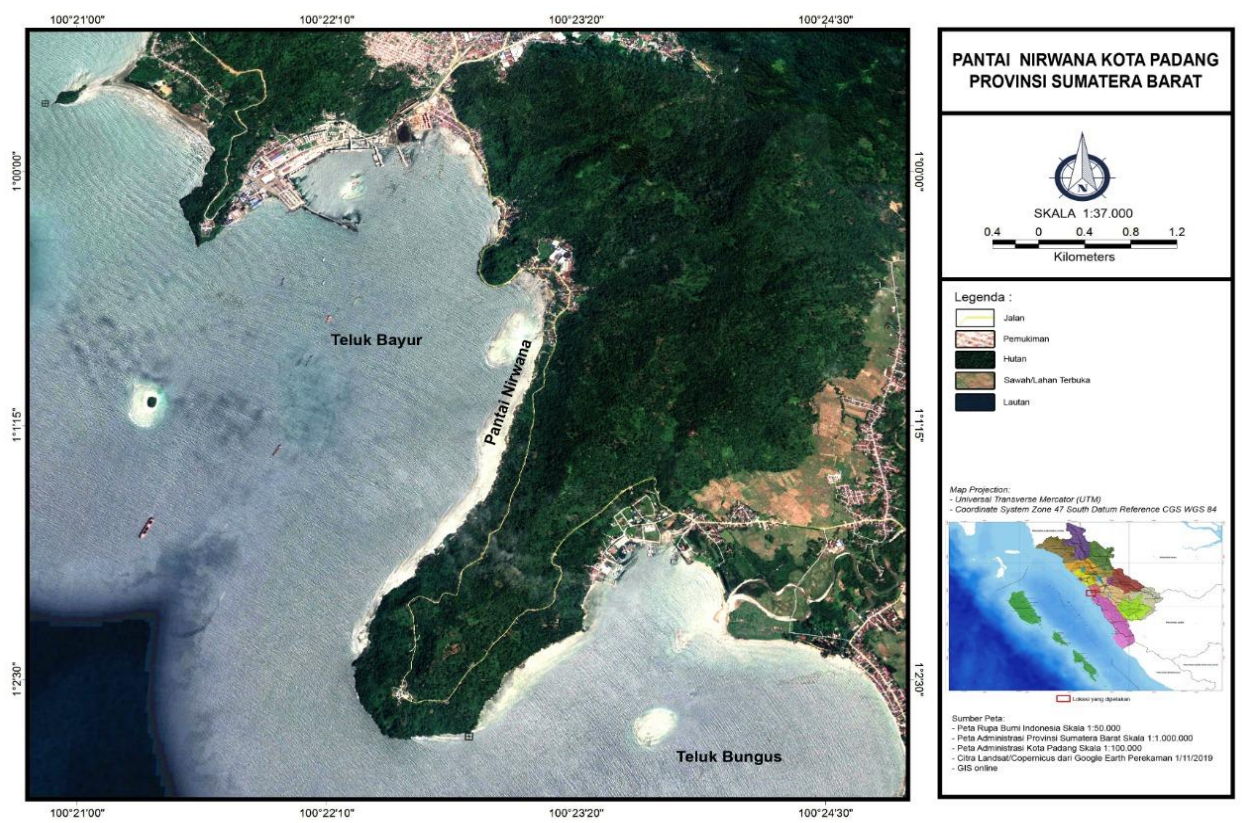

Gambar 1. Peta Lokasi Penelitian

\section{Bahan dan Alat}

Bahan yang digunakan dalam penelitian ini terdiri dari dan lugol untuk mengawetkan sampel. Sementara alat yang digunakan meliputi meteran standar, hand-Held Refractometer dengan merek Dagang Atago, DO meter menggunakam Oksigen Meter merek Ultron DO-5510 untuk mengukur salinitas permukaan air, Termometerstandar air raksa untuk mengukur suhu permukaan air, kekeruhan air menggunakan turbiditimeter standar. Disamping itu juga diambil sampel air untuk mengukur nitrat dan fosfat pada ketiga stasiun penelitian dengan masingmasing jumlah ulangan 3 buah yang kemudian dianalisa di Laboratorium FMIPA UNRI.

\section{Metode yang digunakan}

Penelitian ini menggunakan metode survei, dan yang menjadi sampel adalah makroalgae sebagai salah satu tempat menempel bentik dinoflagellata ini. Dinoflagellata bentik ditemukan hidup di dalam kolom air sebagai fitoplankton, namun sebagian besar besar masa hidupnya menempel pada berbagai substrat yang terdapat di dasar perairan, termasuk makroalga Thallasia sp. Dalam arti kata dinoflagellata ini dapat ditemukan baik pada organisme masih hidup, baik hewan maupun tumbuhan. Dinoflagellata bentik dapat hidup di dasar perairan maupun pada benda mati yang berada di dasar perairan, seperti pada algae, lamun, patahan karang mati (ruble), pasir dan lain-lain. Dalam penelitian ini yang menjadi sampel penelitian adalah lamunyang berada di Perairan Desa Perairan Nirwana Sumatera Barat,dan dalam pengambilan sampelnya dilakukan secara purposif. Sampel yang menjadi pilihan yang berada pada kedalaman sekitar $1 \mathrm{~m}$ pada saat surut dengan kondisi rumpunnya tergolong baik.

Penelitian ini difokuskan pada dinoflagellata bentik Gambierdiscu, Ostreopsis dan Prorocentrum yang menempel pada Thalassia sp yang mengacu pada Omura (2012). Maka pengambilan dilakukan pada kedua sampel dinoplaggellata bentik dan lamun Thalassia sp.Pengamatan dinoflagellata bentik tersebut dilakukan sampel Thallaissia spsekitar 40 gram pada bagian ujungnya sebagai tempat menempel dinoflagellata bentik.

Sementara untuk untuk melihat kepadatan lamun Thalassia sp sendiri diamati menggunakan kuadran $30 \times 30 \mathrm{~cm} 2$ dengan pengambilan sampelnya sebanyak tiga kali sebagai ulangan pada setiap stasiun.Untuk pengambilan sampel makroalga Thallasia sp digunakan purposife sampel masingmasing sebanyak 3 ulangan menggunakan pisau kecil dengan $30 \times 30 \mathrm{~cm}^{2}$. Kemudian dari $30 \times 30 \mathrm{~cm}$ diambil sampel 5 subplot dari 36 subplot $5 \times 5 \mathrm{~m}^{2}$. Data Thallassia sp yang diambil mengacu pada rumpunnya. 


\section{Prosedur Sampling}

Dinoflagellata bentik diamati adalah yang melekat pada Lamun Thalassia sp, Untuk pengamatan dinoflagellate bentik sendiripengambilan sampel dilakukan terhadap Lamun Thalassia sp pada bagian ujungnya sekitar 40 gram setiap sampel.Sementara pengambilan kepadatan lamunThallasia sp sendiri juga diambil diambil dengan bantuan alat snorkeling.Pengambilan sampel dilakukan di Perairan Nirwana, dan sampel yang diambil pada kedalaman sekitar 1,0 m. Untuk mendeteksi lamun menggunakan plot secara acak.

Untuk Lamun Thalassia sp yang diambil lebih kurang 40 gram secara manual menggunakan pisau dan kemudian dengan hati-hati secepatnya dimasukan ke dalam $500 \mathrm{ml}$ kantong plastik (YESOU, 2013). Pengamatan dilakukan di Laboratorium Ilmu Kelautan, Fakultas Perikanan dan Ilmu Kelautan Universitas Riau, dan kemudian diamati di bawah mikroskop stereo (Olympus stereomicroscope; Olympus, Tokyo, Japan).

\section{Analisis data}

Data yang diperoleh dalam penelitian ini dianalisa menggunakan Analisa Statistika. Untuk menganalisis perbedaan diversitas dinoflagellata bentik ketiga genus (Gambierdiscus, Ostreopsis dan Prorocentrum) dilakukan dengan uji statistik Anova dua arah dan kemudian diuji lanjut menggunakan Turkeytest.

\section{HASIL DAN PEMBAHASAN}

Pantai Nirwana merupakan pantai yang indah dan sebagai tempat tujuan wisata di Sumatera Barat. Perairan Nirwana memiliki jarak 11,1 km atau sekitar 22 menit dari Kota Padang. Disamping pantainya memiliki terumbu karang ditumbuhi oleh lamun. Diantara lamun yang dijumpai ditemukan Thalassia sp, yang ditemukan hampir di seluruh perairan dangkal Pantai Nirwana. Kepadatan lamun yang terdapat di perairan Nirwana juga diamati serta beberapa kualitas perairan dengan hasil sebagaimana pada Tabel 1.

Tabel 1. Beberapa parameter kualitas air

\begin{tabular}{llccc} 
& & & Stasiun & \\
\cline { 2 - 4 } No. & Parameter Kualitas Air & 1 & 2 & 3 \\
1 & Kedalaman (m) & 0,64 & 0,42 & 0,28 \\
2 & Salinitas (ppt) & 30 & 30 & 30 \\
3 & Kekeruhan (NTU) & 0,63 & 0,85 & 0,51 \\
4 & Nitrat (mg/l) & 0.093 & 0.077 & 0.070 \\
5 & Posfat (mg/l) & 0.044 & 0.034 & 0.020 \\
\hline
\end{tabular}

Kedalaman perairan pada dasar hampir sama, dan terdapat perbedaan pada ketiga stasiun disebabkan karena waktu pengambilan sampel terjadi pada saat pasang menuju surut terendah. Salinitas sama diantara ketiga stasiun, dan sementara untuk kekeruhan dan konsentrasi nitrat tidak begitu berbeda. Berbeda dengan fosfat yang ditemukan lebih dua kali lipat lebih tinggi pada stasiun satu dibandingkan di stasiun tiga. Boleh jadi disebabkan stasiun satu dekat dengan pemukiman penduduk.

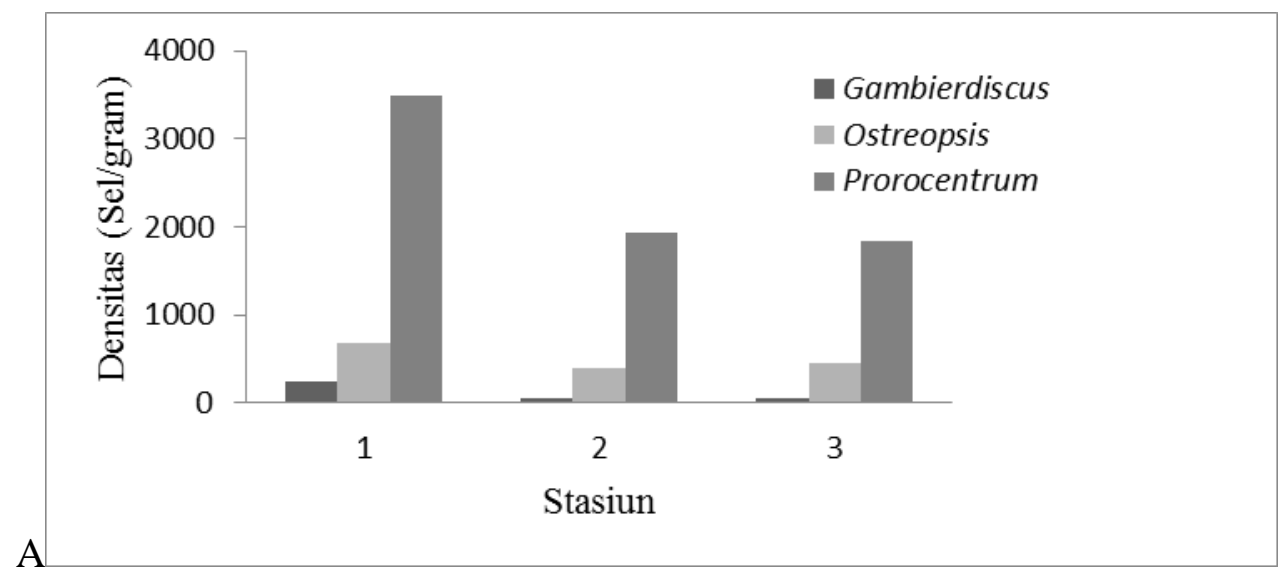




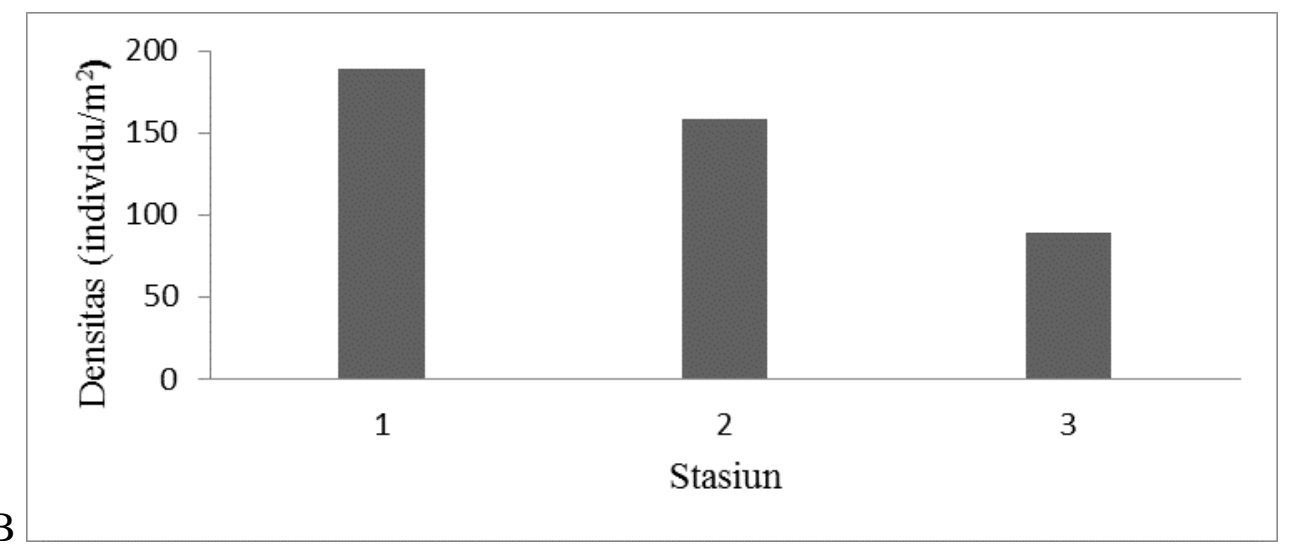

Gambar 2. Rata-rata densitas bentik Dinoflagellata Gambierdiscus, Ostreopsis dan Prorocentrum (A), dan rata-rata kepadatan lamun Thalassia sp pada ketiga stasiun penelitian (B)

Gambar 2A menunjukan bahwa terdapat perbedaan yang mencolok densitas diantara ketiga genus, dimana Prorocentrum memiliki densitas tertinggi diantara ketiga genus, diikuti Ostreopsis dan yang terendah genus Gambierdiscus. Sementara diantara stasiun ditemukan densitas tertinggi pada Stasiun 1 diikuti Satasiun 2 dan yang terendah pada Stasiun 3. Dari uji Statistik Anova dua arah terdapat perbedaan secara nyata diantara stasiun dan genus. Dari uji lanjut Tukey diketahui perbedaan secara nyata terjadi diantara Prorocentrum pada stasiun 1 dengan Prorocentrum Stasiun 3 dan kedua genus Gambierdiscus dan Ostreopsis pada ketiga stasiun. Sementara antara Gambierdiscus yang sama pada syasiun berbeda dan diantara Gambierdiscus dengan Ostreopsis pada stasiun yang dan stasiun berbeda tidak ditemukan perbedaan secara nyata.

Untuk kepadatan lamun Thalassia sp menunjukan kecenderungan yang serupa dengan yang dialami oleh ketiga Dinoflagellata bentikGambierdiscus, Ostreopsis dan Prorocentrum dimana densitas tertinggi ditemukan pada Stasiun 1, kemudian diikuti oleh Stasiun 2 dan yang terendah ditemukan pada Stasiun 3. Dari uji Statistik Anova satu arah ditemukan terdapat perbedaan densitas lamun Thalassia pada ketiga Akan tetapi dari uji lanjut Tukey diketahui bahwa perbedaan secara nyata hanya terjadi diantara Stasiun 1 dan Stasiun 3.

Hasil penelitian ini menunjukan bahwa perbedaan densitas bentik Dinoflagellata Prorocentrum diantara ketiga stasiun kemungkinan berhubungan dengan densitas lamun Thalassia sp. Namun kejadian ini tidak sejalan dengan yang dialami Gambierdiscus dan Ostreopsis. Namun demikian tetap menunjukan kepadatan tertinggi Gambierdiscus dan Ostreopsis terjadi pada Stasiun 1 dibandingkan Stasiun II dan Stasiun III.

Penelitian terakhir terdeteksi Ostreopsis spp. mengalami peningkatan di seluruh perairan yang ditemukan sebelumnya (Vila et al., 2001; Masó et al., 2003; Sansoni et al., 2003; Penna et al., 2005; Turki, 2005) dan pantai bagian timur laut Mediterranean (Aligizaki \& Nikolaidis, 2006; Ismael \& Halim, 2006). Begitupun ancaman bentik dinoflagellata akhir-akhir ini cukup besar, seperti spesies dari genus Gambierdiscus dan Ostreopsis, merupakan kelompok yang memberikan tekanan paling besar terhadap manusia dan kesehatan lingkungan.Gambierdiscus spp. memproduksi gambiertoxin yang menandakan ciguatoxin, zat kimia yang menyebabkan ciguatera yang berhubungan dengan phycotoxin. Toksin ini dapat membuat makanan beracun diseluruh dunia, dan mempengaruhi 25.000 sampai 500.000 manusia setiap tahun (Parsons et al., 2012).

Dalam penelitian ditemukan justru yang tertinggi adalah Prorocentrum. Berhubungan dengan Harmful Algal Bloom (HAB), yang terjadi di Malaysia yang menyebabkan $\mathrm{HAB}$ terjadi disebabkan oleh Pyrodinium bahamense var. compressum semenjak 1976 (Roy, 1977). Namun sejak kejadian tersebut sampai tahun 2009 tidak ditemukan masalah HAB, justru disebabkan oleh dinoflagellata bentik, walau ditemukan beberapa dinoflagellata beracun ditemukan di perairan tersebut. Diantara dinoflagellata bentik tersebut adalah Prorocentrum lima (Mohammad-Noor et al., 2010) dan $P$. rhathymum (Caillaud et al., 2010).

Peningkatan dinoflagellata beracun diperkirakan memiliki hubungan dengan degradasi terumbu karang (Kaly \& Jones 1994). Akan tetapi di dalam penelitian ini lebih dimungkin perbedaan hasil berhubungan dengan kepadatan lamun Thalassia sp sendiri. Dalam hal ini bukan mengacu kepada substrat lamun tetapi kemungkinan terhadap keberadaan substrat yang tersedia. Karena disisi lain dikatakan oleh Vila et al. (2001) bahwa substrat tidak menjadi pilihan dalam penempelan dinoflagellata.

Abrasi terumbu karang boleh jadi berhubungan dengan kelimpahan bentik Dinoflagellata beracun, akan tetapi disebabkan pengaruh tidak langsung degradasi terumbu karang yang menyebabkan peningkatan ketersediaan substrat bagi dinoflagellata. Karena pengaruh kehadiran terumbu karang diperkiran tidak berhubungan dengan peningkatan densitas ketiga bentik dinoflagellata ini, tetapi lebih dimungkinkan oleh kehadiran makroalga atau seagrass sebagai tempat menempel ketiga genus tersebut (Thamrin, 2013 tidak diterbitkan). 


\section{SIMPULAN}

Kesimpulan yang didapatkan dari penelitian ini Dari uji Statistik Anova dua arah, diperoleh perbedaan ketiga spesies antara ketiga secara signifikan. Dengan uji lanjut Tukey, spesies tertinggi secara signifikan hanya antara Stasiun I dan III, dan antara spesies Gabierdiscus dan Ostreosis berbeda nyata dengan ketiga Stasiun dengan Prorosentrum.

Analisis ketiga spesies diperoleh kemungkinan meningkatnya Prorocentrum secara tidak langsung disebabkan rusaknya terumbu karang yang menyebabkan suburnya lamun Thalassia sp yang kemungkinan yang cocok untuk habitat Prorocentrum.

\section{UCAPAN TERIMA KASIH}

Terima kasih kepada penyandang dana LPMP Universitas Riau dan segala pihak yang telah ikut serta dalam pelaksanaan penelitian ini.

\section{DAFTAR PUSTAKA}

Aligizaki, K. G., \& Nikolaidis. (2006). The presence of the potentially toxic genera Ostreopsis and Coolia (Dinophyceae) in the North Aegean sea, Greece, Harmful Algae 5, p. 717-730.

Al-Has, A., \& Mohammad-Noor, N. (2011). Identification of marine sand-dwelling dinoflagellates in Dinawan Island, Sabah. Borneo Science. 37-45.

Caillaud, A., Fraga, S., Aligizaki, K., MohammadNoor, N., Nikolaidis, G., Moestrup, Ø., \& Diogène, J. (2009), Desarrollo de un ensayo celular para la detección de maitotoxinas en Gambierdiscus spp. Estudio comparativo entre cepas de distintas procedencias. X Reuniao Oberica, Fitoplancton Toxico e Biotoxinas, Lisbon.

Chui-Pin, L., L. Po-Teen, C. Kok-Wah, N. BoonKoon \& G. Usup. (2010). Morphology and molecular characterization of a new spesies of thecate bnethic dinoflagellate, coolia malayensis sp. NOV. (Dinophyceae)1. J. Phycol. 46, 162-171

Chui-Pin, L.,Po-Teen L.,Toh-Hii T., Tuan-Halim, T. N., Kok-Wah C., Boon-Koon N. \& Usup G. (2011).First report of the benthic dinoflagellate, ambierdiscus belizeanus (Gonyaulacales: Dinophyceae) for the east coast of Sabah, Malaysian Borneo. Phycological Research.59:143146.

Harrness. (2005). Harmful Algal Research and Response: A National Environ-mental Science.

Holmes, M.J., Lee, F.C., Ming Teo, S.L., Woo Khoo, H. (1998). A survey of benthic dinoflagellates on Singapore reefs. In: Reguera B, Blanco J, Fernández ML, Wyatt $\mathrm{T}$ (eds) Harmful algae. Intergovernmental Oceanographic Commission of UNESCO, Xunta de Galicia, Vigo, p 50-51.

Ismael, A.A. \& Halim, Y. (2006), First record of Ostreopsis spp. in Egyptian waters with a description of $O$. mediterraneus $\mathrm{n}$. sp. 12th International conference on Harmful Algae, Copenhagen, pp. 197.

Iwataki, M.H., Kawami, N., Van Nguyen,L. Quang Doc,T. That Phap,Y. Fukuyoand K. Matsuoka. (2009). Cellular and body scale morphology of Heterocapsa huensis sp. nov. (Peridiniales, Dinophyceae) found in Hue, Vietnam. Phycological Research; 57: 87-93

Kaly, U. \& Jones, G.P. (1994). Test of the effect of disturbance on ciguatera in Tuvalu. Memoirs of the Queensland Museum 34, 523-532.

Lewis, R.L. (2001). The changing face of ciguatera. Toxicon 39, 97-106.

Loeblich, A. R. III (1968). A new marine dinoflagellate genus, Cachonina, in axenic culture from the Salton Sea, California with remarks on the genus Peridinium. Proc. Biol. Soc. Wash. 81: 91-6.

Masó, M., Garcés, E., Pages, F., Camp, J. (2003), Drifting plastic debris as a potential vector for dispersing Harmful Algal Bloom (HAB) species, Scientia Marina 67, p. 107-111.

Mohammad-Noor, N., Daugbjerg, N., Moestrup, Ø., \& Anton, A. (2007). Marine epibenthic dinoflagellates from Malaysia - a study of live cultures \& preserved samples based on light \& scanning electron microscopy. Nordic Journal of Botany 24(6): 629-690.

Murray, S., Hoppenrath, M., Larsen, J., \& Patterson, D.J. (2006). Bysmatrum teres sp. nov., a new sand-dwelling dinoflagellate from northwestern Australia. Phycologia 45: 161-167

Norris, D.R., Bomber, J.W., Balech, E. (1985). Benthic dinoflagellates associated with ciguatera from the Florida Keys. I. Ostreopsis heptagona sp. nov. In: Anderson DM, White AW, Baden DG (eds) Toxic dinoflagellates. Elsevier Science, New York, p 39-44.

Omura, T., Iwataki, M., Borja, V. M., Takayama, H., \& Fukuyo, Y. (2013). Marine Phytoplakton of Western Pacific. Kouseisha Kouseiki Co., Ltd. Tokyo. 160 halaman.

Park, D.L. (1994). Reef Management and seafood monitoring programs for ciguatera. Memoirs of the Queensland Muesum 34, 587-594.

Parsons, M.L., Aligizaki, K., Bottein, M.D., Fraga, S., Morton, S.L., Penna, A., \& Rhodes, L. (2012). Gambierdiscus and Ostreopsis: Reassessment of the state of knowledge of their taxonomy, geography, ecophysiology, and toxicology. Harmful Algae 14: 107-129.

Pearce, I., J.A. Marshall., \& Hallegraeff, G.M. (2001). Toxic epiphytic dinoflagellates from east coast Tasmania, Australia. In: Hallegraeff GM, Blackburn SI, Bolch CJ, Lewis RJ (eds) Harmful algal blooms 2000. Intergovernmental Oceanographic Commission of UNESCO, Hobart, Tasmania, p 54-57

Penna, A., Vila, M., Fraga., S., Giacobbe, M.G., Andreoni, F., Riobó, P. \& Vernesi, C. (2005). Characterization of Ostreopsis and Coolia 
(Dinophyceae) isolates in the western Mediterranean Sea based on morphology, toxicity and internal transcribed spacer $5.8 \mathrm{~s}$ rDNA sequences, Journal of Phycology 41, p. 212-225.

Pottier, I., Vernoux, J.P., \& Lewis, R.J. (2001). Ciguatera fish poisoning in the Caribbean Islands and Western Atlantic. Rev. Environ. Contam. Toxicol. 168, 99-141.

Roy, R.N. (1977). Red tide \& outbreak of paralytic poisoning in Sabah. Medical Journal of Malaysia 31: 247-251.

Sansoni, G., Borghini, B., Camici, G., Casotti, M., Righini, P., \& Rustighi, C. (2003). Fioriture algali di Ostreopsis ovata (Gonyaulacales: Dinophyceae): un problema emergente, Biologia Ambientale 17, p. 17-23.

Turki, S. (2005). Distribution of toxic dinoflagellates along the leaves of seagrass Posidonia oceanica and Cymodocea nodosa from the Gulf of Tunis, Cahiers De Biologie Marine 46, p. 29-34.
Vila, M., Garcés, E., \& Masó, M. (2001). Potentially toxic epiphytic dinoflagellate assemblages on macroalgae in the NW Mediterranean, Aquatic Microbial Ecology 26, p. 51-60.

Watanabe, M. M., M. Kawachi, M. Hiroki, and F. Kasai. (2000). NIES-collection. List of Strains, 6th edn. Microalgae and Protozoa. National Institute of Environmental Studies, Tsukuba, Japan, 159 pp.

YESOU. (2013). Use of Artificial Subtrate to Assee Field Abundance of Banthic HAB (BHAB) Dinoplagellates. Project Imformation and Methods. 9 halaman

Yamaguchi, M., Itakura, S., Nagasaki, K., Matsuyama, Y., Uchida, T., \& Imai, M. (1997). Effects of temperature and salinity on the growth of the red tide flagellates Heterocapsa circularisquama (Dinophyceae) and Chattonella verruculosa (Raphidophyceae). J. Plankton Res. 19: 1167-74. 